\title{
6. 各社操業実績
}

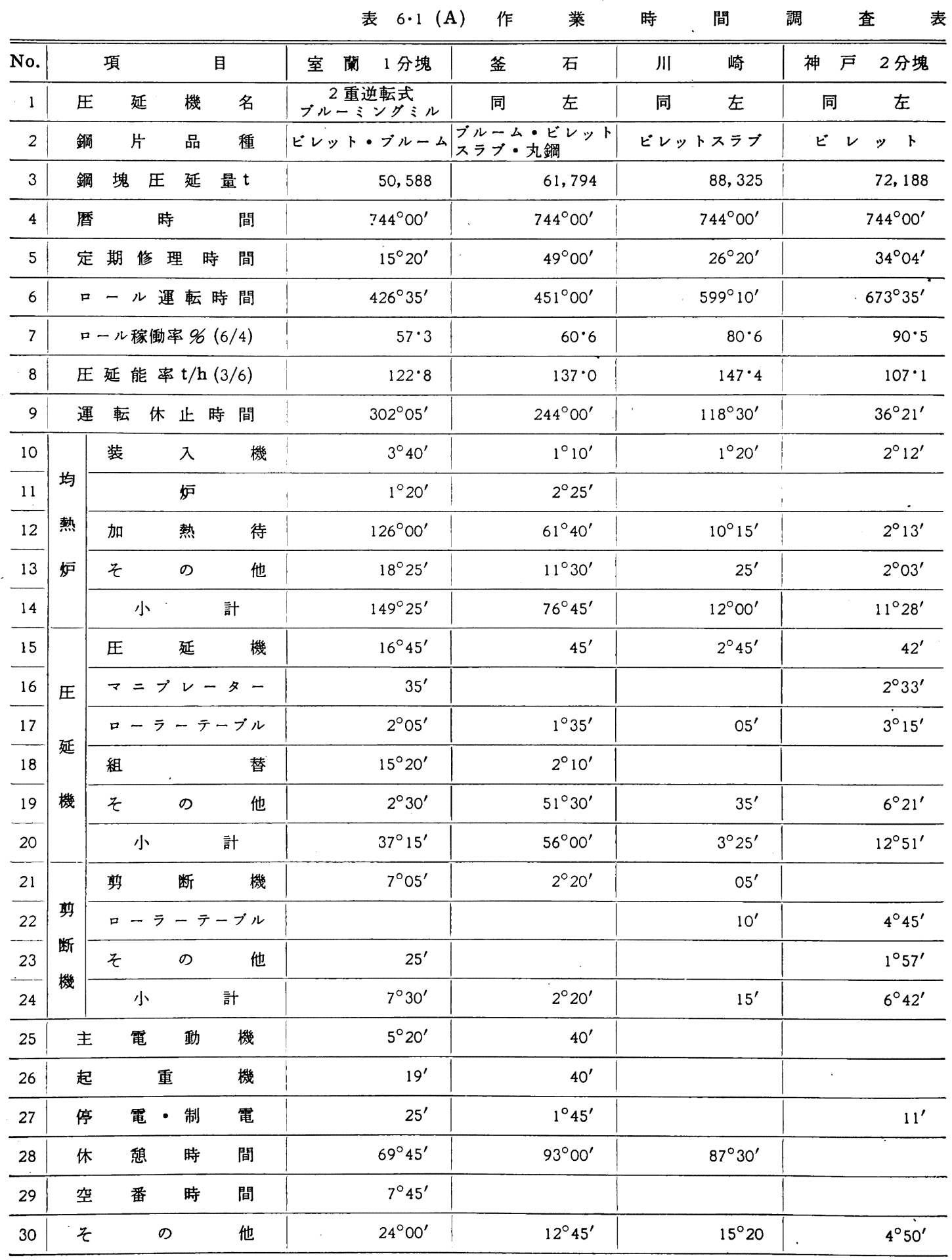




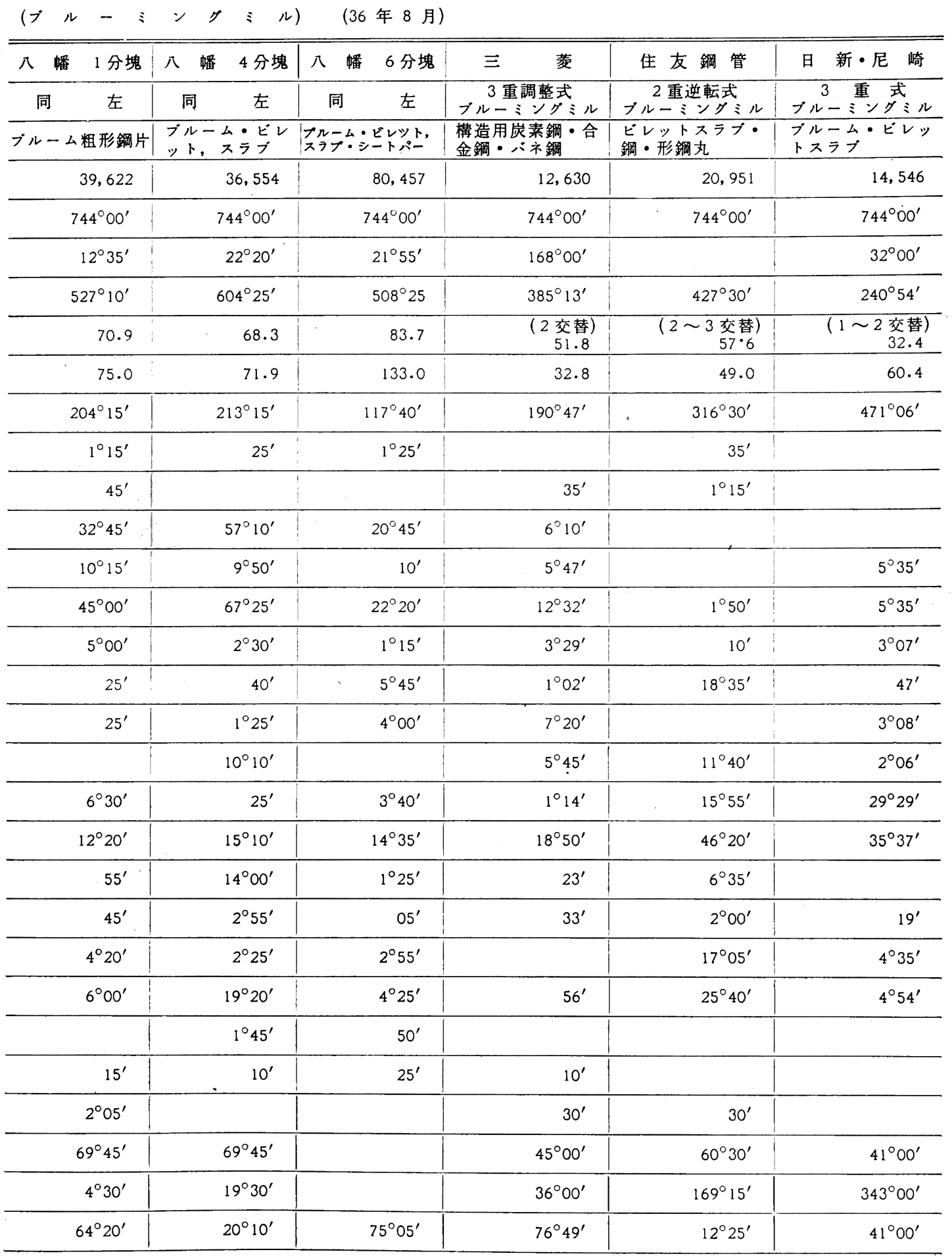


表6.1（B）作 業 時間 調 查 表

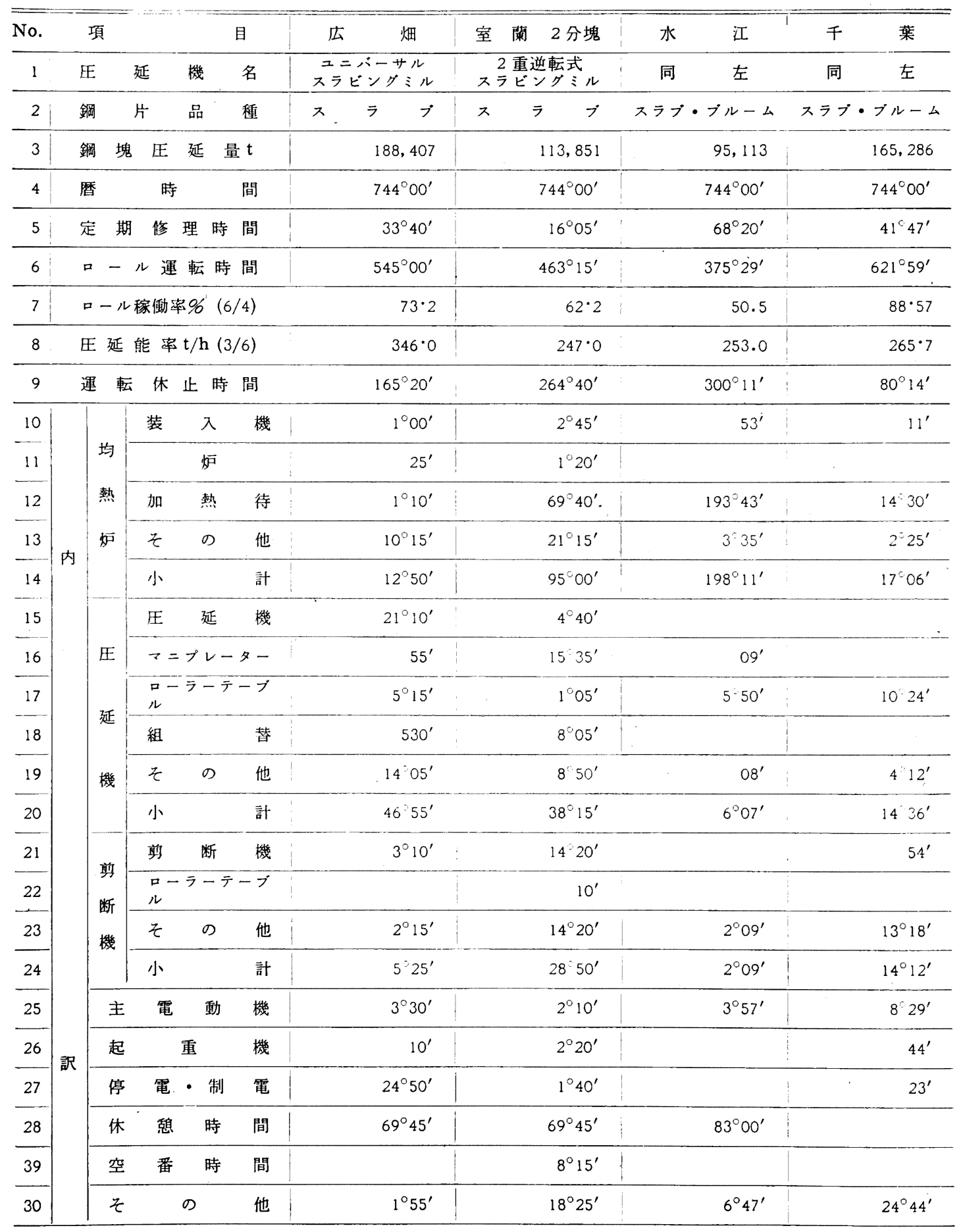


(スラビングミル) (36 年 8 月)

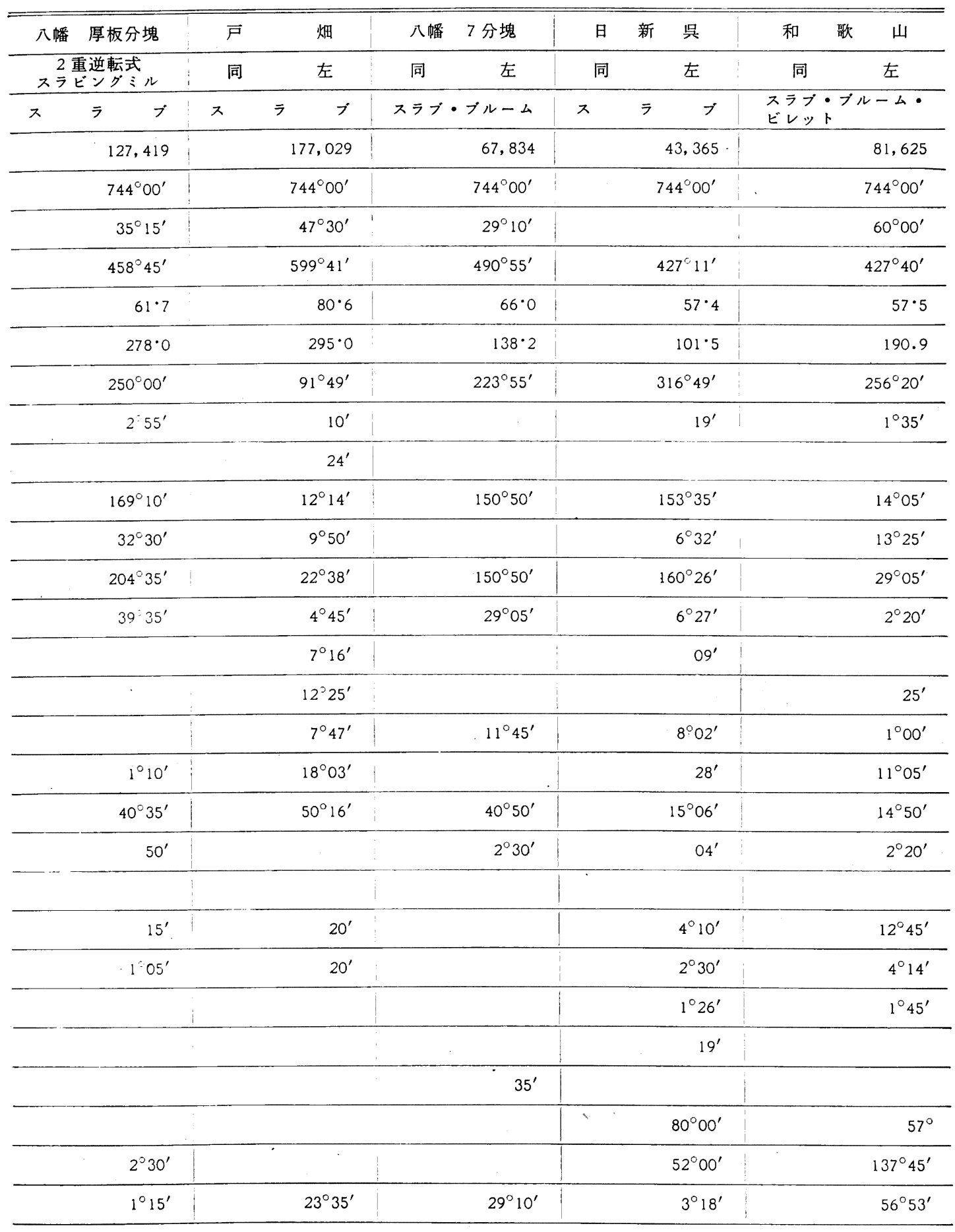




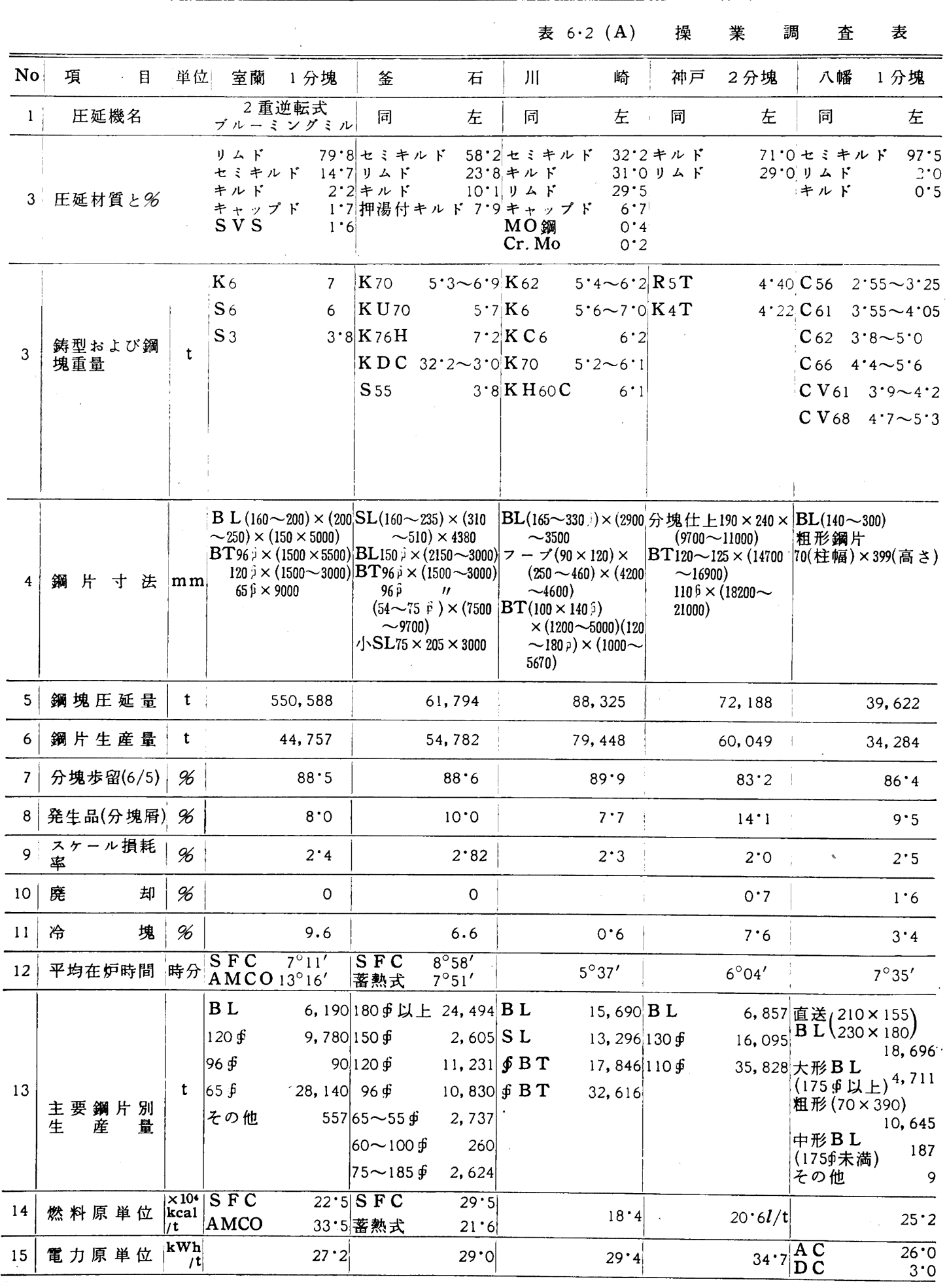




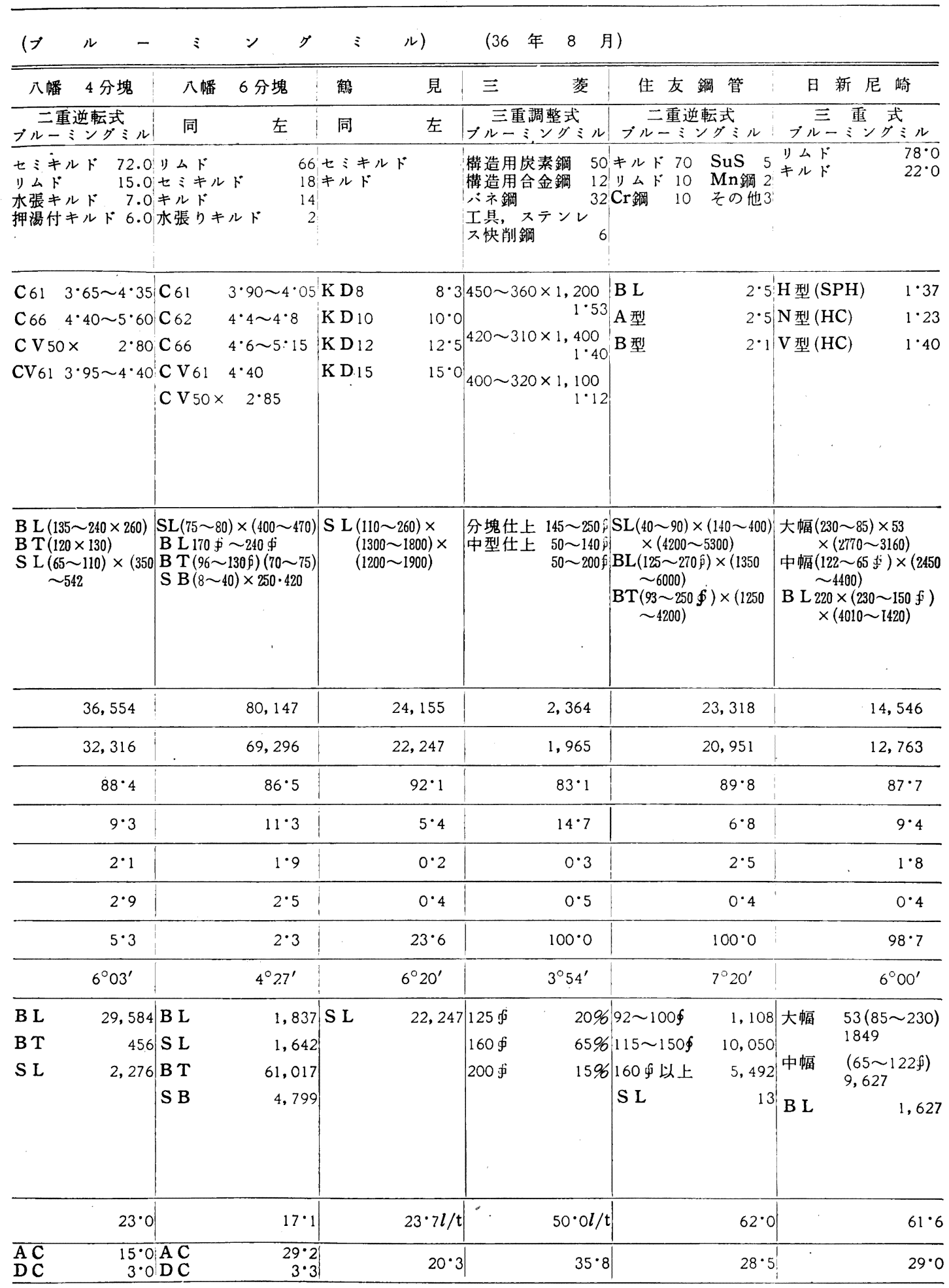




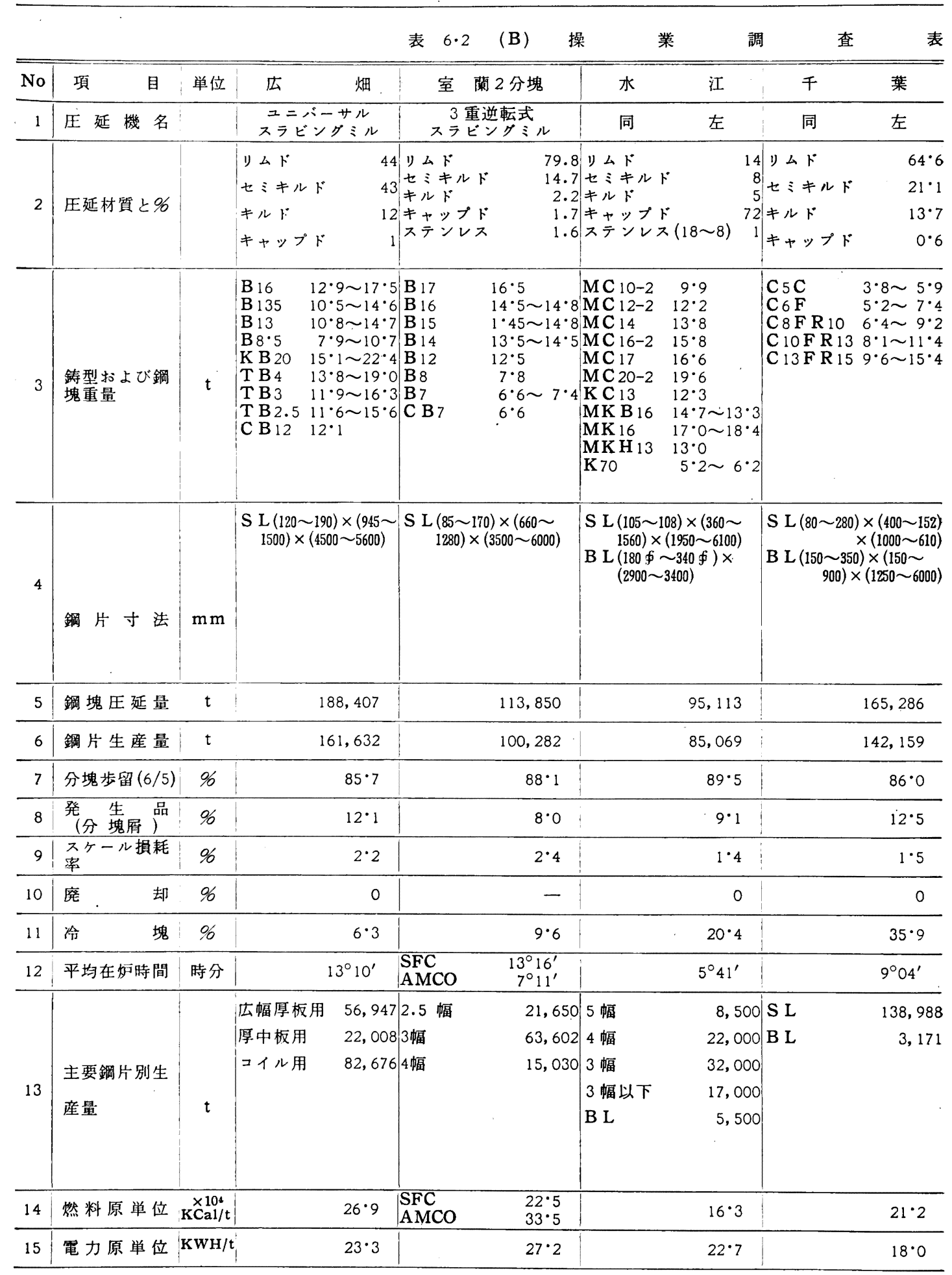


(スラピングミ ル) (36 年 8 月)

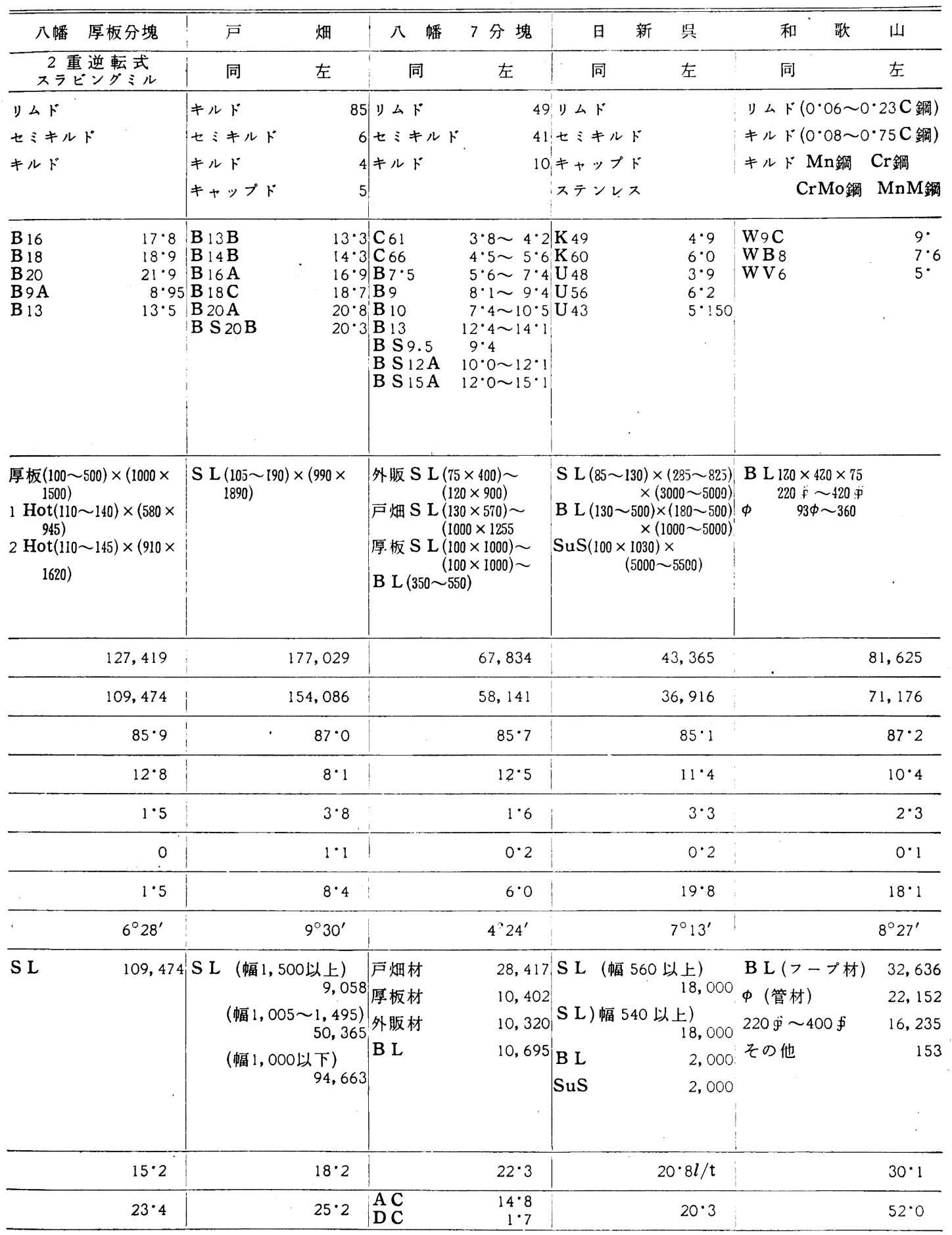

